\title{
foF2 Long-Term Trend at a Station Located near the Crest of the Equatorial Ionization Anomaly
}

\section{Doua Allain Gnabahou, Sibri Alphonse Sandwidi, Frédéric Ouattara}

Laboratoire de Recherche en Energétique et Météorologie de l'Espace (LAREME) de l'Université Norbert ZONGO, Koudougou, Burkina Faso

Email: gnabahou@yahoo.fr

How to cite this paper: Gnabahou, D.A., Sandwidi, S.A. and Ouattara, F. (2020) foF2 Long-Term Trend at a Station Located near the Crest of the Equatorial Ionization Anomaly. International Journal of Geosciences, 11, 518-528.

https://doi.org/10.4236/ijg.2020.118027

Received: July 3, 2020

Accepted: August 14, 2020

Published: August 17, 2020

Copyright $\odot 2020$ by author(s) and Scientific Research Publishing Inc. This work is licensed under the Creative Commons Attribution International License (CC BY 4.0).

http://creativecommons.org/licenses/by/4.0/

\begin{abstract}
Critical frequency foF2 long-term trends at Dakar station $\left(14.4^{\circ} \mathrm{N}, 342.74^{\circ} \mathrm{E}\right)$ located near the crest of the equatorial ionization anomaly EIA, are analysed taking into account geomagnetic activity, increasing greenhouse gases concentration and Earth's magnetic field secular variation. After filtering solar activity effect using F10.7 as a solar activity proxy, we determined the relative residual trends slopes $\alpha$ values for three different levels of geomagnetic activity. For example, at $1200 \mathrm{LT}$, the value of $\alpha$ goes from $-0.27 \%$ /year for very magnetically quiet days to $-0.19 \% /$ year for magnetically quiet days and to $-0.13 \% / y e a r$ for all days. It appears from the slopes $\alpha$ obtained, that they increase with the level of geomagnetic activity and their negative values are qualitatively consistent with the expected decreasing trend due to the increase in greenhouse gases concentration but are greater than $0.003 \% /$ year which would result from a $20 \%$ increase in $\mathrm{CO}_{2}$ emissions which actually took place during the analysis period. Regarding Earth's magnetic field magnitude, B secular variation and the dip equator secular movement, Dakar station is located near the crest of the equatorial ionization anomaly, Earth's magnetic field magnitude, B decreases there and the trough approaches the position of Dakar during the period of analysis. These two phenomena induce a decrease in foF 2 which is in agreement with the decreasing trend observed at this station.
\end{abstract}

\section{Keywords}

Geomagnetic Activity, Long-Term Trend, foF2, Dip Equator

\section{Introduction}

The extreme weather phenomena increasingly observed in recent decades are for 
many scientists rightly or wrongly linked to the increase in anthropogenic emissions of greenhouse gases which influence the troposphere and the climate [1]. The upper atmosphere, particularly ionosphere, is also affected by these changes observed at low altitude. Since the pioneering study [2], investigations of long-term changes in the ionosphere have become an important topic in climate change research and many results have been published during these last thirty years [1] [3]-[36]. The ionosphere, in particular its F layer, plays an important role in radio communications (HF) and the propagation of GPS (Global Positioning System) signals, and most studies on its long-term variations use the critical frequency of its F2 layer (foF2) directly linked to its electronic density.

Today, several possible mechanisms [15] [20] [30] [37] are used to explain the long-term trends of foF2, among others: 1) solar cycle long term variation, 2) long term variation in geomagnetic activity, 3) increasing greenhouse gases concentration and 4) secular Earth's magnetic field variation.

For the first mechanism, it is important to note that solar activity is the main source of ionization and it is always filtered from trends to focus only on the other mechanism's effects.

Thus, this first group of authors links the trends to geomagnetic activity long term variation [12] [13] [27] [28] [35] [36] [38] [39]; the second group links ionosphere trends to the increasing greenhouse gases concentration [2] [3] [4] [6] [7] [40] [41] [42] [43] and the last third group explains the trends by the secular variation of Earth's magnetic field [10] [14] [15] [36] [36].

In this work, we analyse for the first time the long-term variations of foF2 from a West African equatorial station, located near the crest of the equatorial ionization anomaly EIA. It should be noted that very few studies have been devoted to long-term variations in the area of the West African equatorial ionization anomaly. We can cite the work of [15] and [30] who looked at long-term trends at Ouagadougou station, which is located near the trough of the West African equatorial ionization anomaly.

[30] studied foF2 long-term diurnal, seasonal and annual trends at the Ouagadougou station. He came to the following conclusions: foF2 average diurnal, seasonal and annual trends are decreasing over the study period, negative trends are observed during the day and positive trends at night at $10 \mathrm{LT}$; the absolute values of the trends are higher at night than during the day; the absolute values of the trends are higher in summer than in winter; at 4 LT when the greatest positive trend is observed, the trend is positive from 1966 to 1981 and negative from 1981 to 1996 , at 19 LT when the largest negative trend is observed, the trend is negative for the entire period of analysis from 1966 to 1996 . Concerning Earth's magnetic field secular variation influence, [30] estimates by a qualitative analysis that this can be a mechanism capable of producing some of the observed trends. As for the influence of geomagnetic activity, he observes that during certain hours (early in the morning and early in the evening), the variations in foF2 are well correlated with Ap index. 
[15] studied the effects of the increase in greenhouse gases and the displacement of the magnetic dip equator on foF2 long-term trend in the same station. They obtained the following results: a downward trend of $-0.015 \mathrm{MHz} /$ year is obtained, i.e. a decrease of $\sim 5 \%$ over the 33 -year period considered. The downward trend is qualitatively consistent with an expected downward trend in the increase in greenhouse gas concentrations, but is not sufficient to produce the observed trend. The magnetic dip equator displacement to Ouagadougou position brings it closer to the equatorial ionization anomaly's trough. This factor added to that of greenhouse gases may explain the negative trend observed.

The present paper goal is to analyze foF2 long-term trend of the African EIA sector. To contribute to the knowledge of the ionosphere in general and particularly the equatorial ionization anomaly region, we analyze for the first time, foF2 long-term trends of a station located near the equatorial ionization anomaly's crest. The aim of this article is to analyze F2 layer critical frequency long-term trends at Dakar station, taking into account the effects of greenhouse gases, geomagnetic activity and Earth's magnetic field secular variation. The main lines of the work are as follows: the data analysis is presented in Section 2 and in Section 3, we present our results and their discussion as well as a conclusion in Section 4 .

\section{Data Analysis}

In this section, we will analyse the long-term annual trends of foF2 parameter measured at Dakar station $\left(14.4^{\circ} \mathrm{N}, 342.74^{\circ} \mathrm{E}\right)$, over the period from 1964 to 1996, ie over 3 solar cycles from minimum to minimum to decrease the effect of the solar cycle on all the data analysed, as [22] did.

Regarding the high correlation coefficients between foF2 and F10.7, to filter out the solar activity effect, we used a linear regression between foF2 and F10.7 (solar radio noise at $\lambda=10.7 \mathrm{~cm}$ ). [44] showed that correction of solar activity with use of F10.7 gave more significant trends than with Rz. In addition, it is very well known the high correlation coefficient between foF2 and F10.7, precisely because F10.7 is an excellent proxy of solar EUV. foF2 and F10.7 data are available respectively on the sites: http://www.ips.gov.au/, https://www.ukssdc.ac.uk/. This linear regression results in the following equation:

$$
\text { foF } 2_{\text {est }}=a \mathrm{~F} 10.7+b
$$

$a$ and $b$ are real coefficients determined by using least squares method. To determine foF2 trends we follow [27] by using relative deviation expression of the observed foF 2 values Equation (2). The relative deviation expression has been proposed by [39] [40] and used in many publications.

$$
\delta \mathrm{foF} 2=\frac{\mathrm{foF} 2_{\mathrm{obs}}-\mathrm{foF} 2_{\text {est }}}{\mathrm{foF} 2_{\text {est }}}
$$

with foF $2_{\text {obs }}$, the observed value. 
To take into account long-term trends in geomagnetic activity, we will compare the trends of $\delta f \circ 2$ for three levels of geomagnetic activity: 1) magnetically very quiet days ( $\delta$ foF2_vquiet), 2) magnetically quiet days ( $\delta f \circ F 2$ quiet) and 3) all days ( $\delta$ foF2_all) using the criteria: aa < $20 \mathrm{nT}$ : magnetically quiet days; aa < $10 \mathrm{nT}$ : magnetically very quiet days.

Our foF 2 trend is determined by using:

$$
\delta \text { foF } 2=\alpha \text { Time }+\beta
$$

with $\alpha$ and $\beta$ real coefficients obtained by least squares method. The test of the significance of the linear trend parameter (the slope $\alpha$ ) was done with Fisher's F criterion with a confidence level $\geq 95 \%$.

$$
F=r^{2}(N-2) /\left(1-r^{2}\right)
$$

where $r$ is the correlation coefficient between $\delta f \circ 2$ and year after Equation (2), and $N$ is the number of pairs considered.

Mann Kendall's non-parametric trend test with 95\% significance level was also applied to the slope $\alpha$. It should be noted that only the slopes obtained between 1200 LT and 1700 LT have a significance level more than 95\% with this test and for the three levels of geomagnetic activity considered. In the following we only consider those hours.

\section{Discussion and Results}

Figure 1 shows the trends slopes diurnal variations of $\delta f \circ 2$ at Dakar station for three geomagnetic activity levels. Blue curve corresponds to all days, red curve to quiet days and green curve to very quiet days. Error indicated as vertical bars. It appears from Figure 1 that the hourly slopes are negative from 1200 LT to 1700 LT for the three curves. Table 1 summarizes the slopes of trend for very quiet, quiet and all days. These negative trends, the weakest of which is $0.13 \% /$ year ( $\delta$ foF2_all at 1200 LT) are qualitatively in agreement with those obtained by [30] and [15] at Ouagadougou station. [30] found a negative slope of $0.7 \% /$ year at 1200 LT while [15] at the same time found a negative slope of $0.2 \%$ year at Ouagadougou station, located near the trough of the equatorial ionization anomaly region.

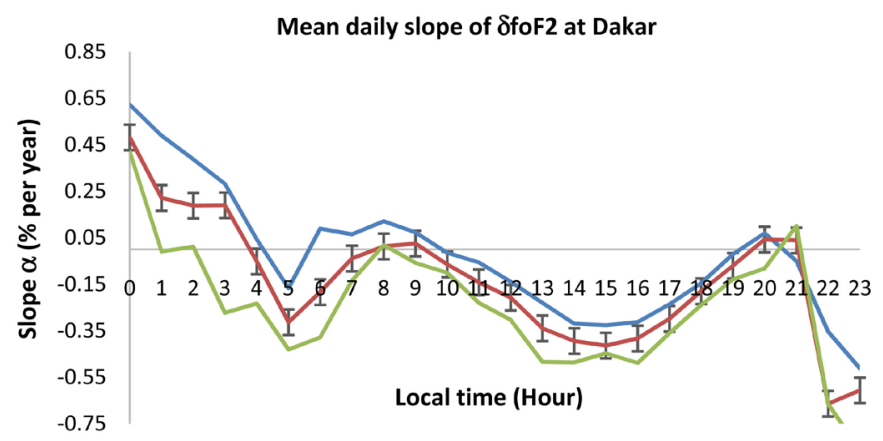

Figure 1. Diurnal variation of annual mean $\delta f \circ 2$ slope for three geomagnetic activity levels. 
Table 1. Hourly trend slope for very quiet, quiet and all days.

\begin{tabular}{cccc}
\hline \multirow{2}{*}{ Local time (Hour) } & \multicolumn{3}{c}{ Trend slope $\alpha$ per year } \\
\cline { 2 - 4 } & $\delta$ foF2_vquiet & ofoF2_quiet & ofoF2_all \\
\hline 1200 & -0.0027 & -0.0019 & -0.0013 \\
1300 & -0.0043 & -0.0033 & -0.0025 \\
1400 & -0.0046 & -0.004 & -0.0032 \\
1500 & -0.0043 & -0.0039 & -0.0031 \\
1600 & -0.0042 & -0.0034 & -0.0027 \\
1700 & -0.0034 & -0.0027 & -0.002 \\
\hline
\end{tabular}

The decreasing trend observed at Dakar station is qualitatively consistent with an expected downward trend, due to increase in greenhouse gases concentration. However, the trends observed between $1200 \mathrm{LT}$ and $1700 \mathrm{LT}$ are greater than the $0.003 \%$ /year which would result from a $20 \%$ increase in $\mathrm{CO}_{2}$ emissions which actually took place during the analysis period, extrapolating the results of [41] and [42] for a doubling in $\mathrm{CO}_{2}$ concentration. [15] obtained the same negative trend but also higher in Ouagadougou than the expected effect of greenhouse gases. The large negative trend in magnitude observed during this study shows that the effect of the increase in greenhouse gases concentration may be not enough to induce the observed trends.

To analyse the effect of geomagnetic activity, instead of filtering it, we will compare ofoF2 trends slopes for three levels of geomagnetic activity that are those of very quiet, quiet and all days. [28] has shown that any type of Ap (monthly or annual average values) or Ap filtration by regression can only partially suppress geomagnetic activity. Figure 2 shows the annual variations of ofoF2 at $1500 \mathrm{LT}$ at Dakar. Blue curve corresponds to all days, red curve corresponds to quiet days and green curve corresponds to very quiet days. It appears from Figure 2 that $\delta f \circ F 2$ trend slope at 1500 LT decreases in absolute value when we go from very quiet days, to quiet days and then all days. Table 1 summarizes the trends slopes obtained between $1200 \mathrm{LT}$ and $1700 \mathrm{LT}$ for the three levels of geomagnetic activity. It appears from Table 1 that $\delta f \circ 2$ trends slopes between 1200 LT and 1700 LT decrease in absolute value when the level of geomagnetic activity increases. The slope of the trend at $1500 \mathrm{LT}$ for example goes from $-0.43 \% /$ year for very quiet days to $-0.39 \%$ /year on quiet days then to $-0.31 \% /$ year for all days. It's a $0.04 \% / y e a r$ decrease in slope when going from very quiet days to quiet days. The intensification of geomagnetic activity therefore produces an absolute decrease in trend slope. This variation due to geomagnetic activity remains low in this station because the error bars in Figure 2 indicate that curves of the three levels of geomagnetic activity are almost identical.

The influence of Earth's magnetic field secular variation on foF2 long-term variations can be classified into: 1) the long-term variation of the inclination I 


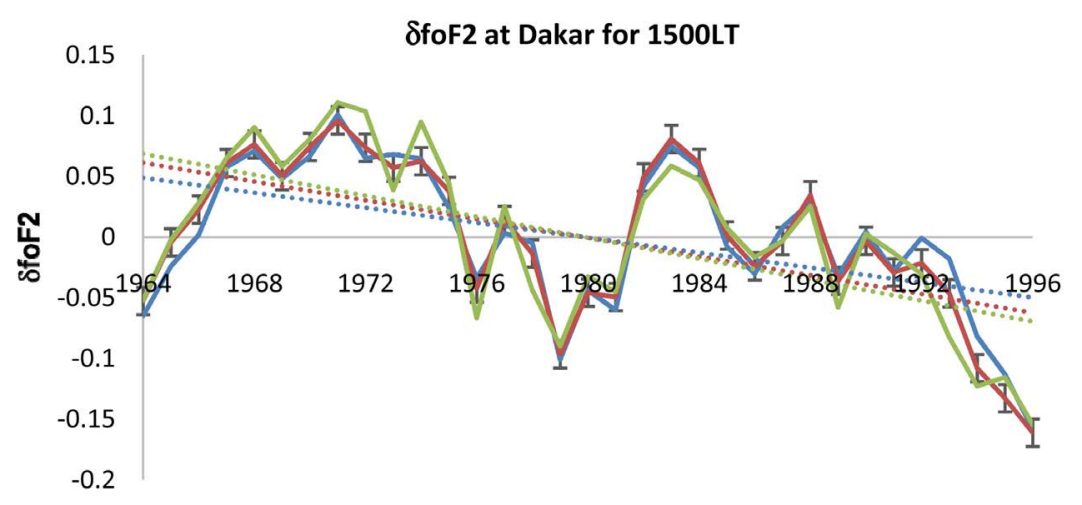

Figure 2. Annual variation of $\delta f \circ F 2$ at Dakar for 1500 LT.

and the declination D, 2) the long-term variation of Earth's magnetic field magnitude $B$ and 3) the displacement of dip equator. These three parameters were obtained from the International Geomagnetic Reference Field (IGRF). Figure 3 shows that the factors in (I) cos (I) decreases during the period considered, as the inclination I (Figure 4) at Dakar station. A decrease in the factors in (I) cos (I) should induce an increase in foF2 during the daytime instead of the decrease observed between 1200 LT and 1700 LT [15] [45]. Regarding factor cos (D) cos (I) which is also shown in Figure 3, it increased during the study period. This increasing trend should also induce a positive trend of foF2, instead of the negative trend observed as shown by [36] for equatorial stations.

Figure 4 shows Earth's magnetic field magnitude B variations at Dakar station (blue line). Earth's magnetic field magnitude B influences the vertical drift. Indeed, in $\mathrm{F}$ region, the phenomenon of equatorial fountain produces on one hand intensification of the ionization at more or less $15^{\circ}$ of latitude (crest EIA) on both sides of dip equator and on the other hand a decrease in ionization in the trough of the EIA. Thus, a decrease in B will induce a further decrease in foF2 in stations located on the crest and a decreasing trend will then be expected. This is the case with the decreasing trends obtained between 1200 LT and 1700 LT.

Regarding the dip equator displacement, its latitudinal movement is shown in Figure 5 at the geographic longitude of Dakar. Dakar is located near the crest of the equatorial ionization anomaly EIA and one can see that dip equator approaches the latitude of Dakar during the study period. This displacement of the equatorial anomaly trough towards Dakar will induce foF2 variations. To show qualitatively this displacement impact, we determined foF2 for different latitudes at the geographical longitude of Dakar for three different dates with IRI-2016 available on http://omniweb.gsfc.nasa.gov/. Figure 5 shows foF2 latitudinal profile at the geographic longitude of Dakar for three years (1964, 1980 and 1996) under the initial conditions: January, 1500 LT with F10.7 $=150$. From 1964 to 1996, the equatorial ionization anomaly trough approached Dakar's position and foF2 should decrease. The same results were obtained for other stations under EIA: Ouagadougou $\left(12.4^{\circ} \mathrm{N}, 358.5^{\circ} \mathrm{E}\right)$, Huancayo $\left(12.0^{\circ} \mathrm{S}, 284.7^{\circ} \mathrm{E}\right)$ and PhuThuy $\left(21.3^{\circ} \mathrm{N}, 106.0^{\circ} \mathrm{E}\right)$, obtained respectively by [15] [43] [46]. 


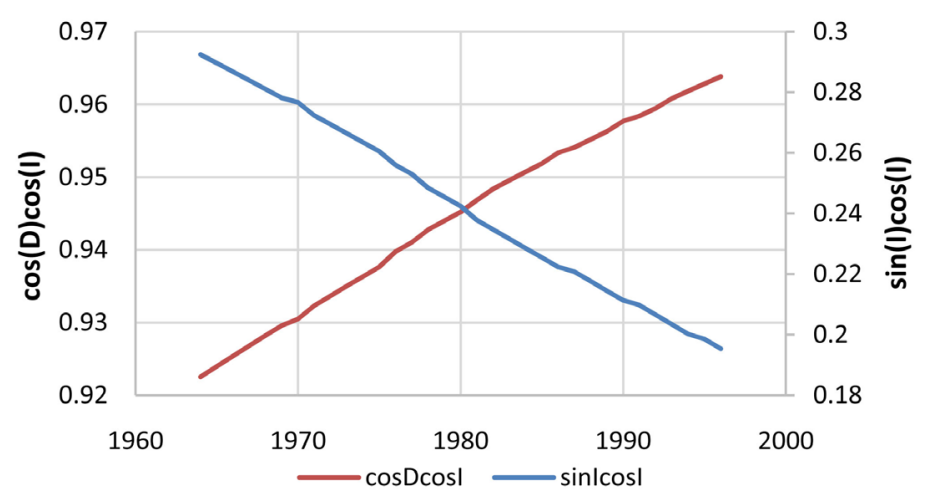

Figure 3. $\sin (\mathrm{I}) \cos (\mathrm{I})$ factor and $\cos (\mathrm{D}) \cos (\mathrm{I})$ factor. Inclination I and declination D obtained from the International Geomagnetic Reference Field IGRF, at Dakar location $\left(14.4^{\circ} \mathrm{N}, 342.74^{\circ} \mathrm{E}\right)$.

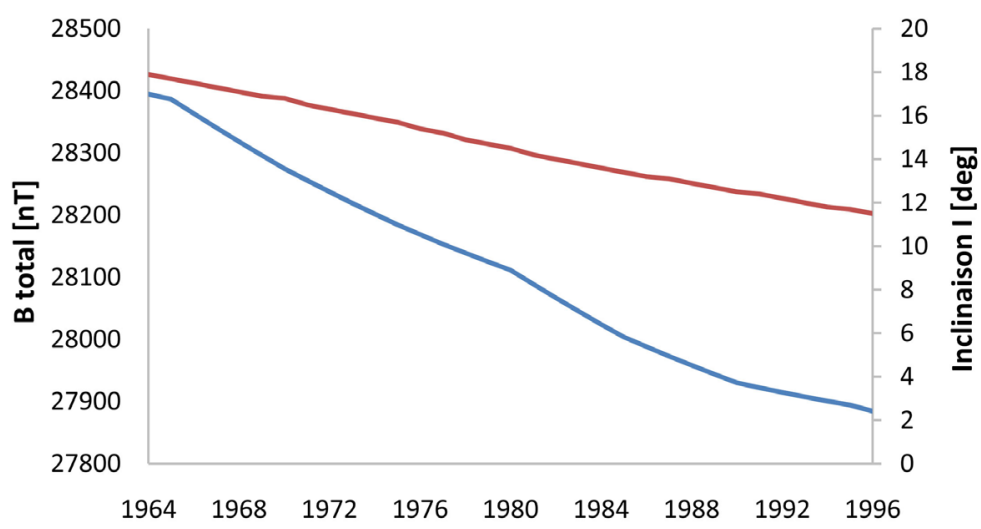

Figure 4. Inclination I (red line) at $300 \mathrm{~km}$ height and Earth's magnetic field magnitude B (blue line) obtained from the International Geomagnetic Reference Field IGRF, at Dakar location $\left(14.4^{\circ} \mathrm{N}, 342.74^{\circ} \mathrm{E}\right)$.

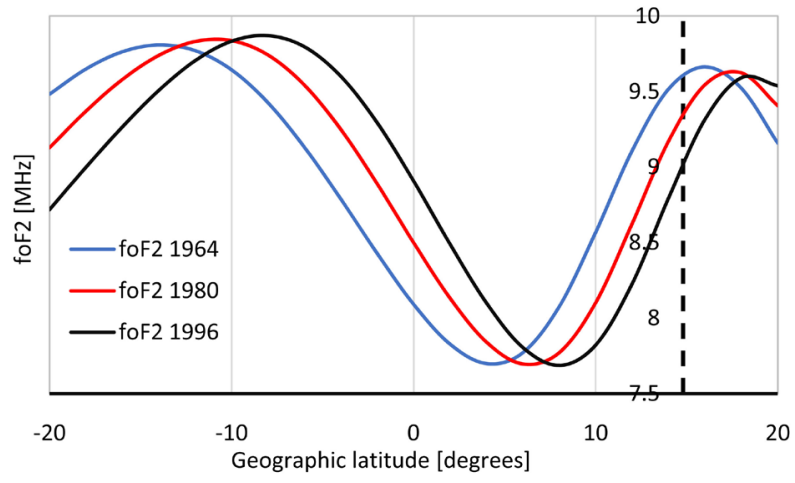

Figure 5. Latitudinal profile of foF2 at the geographic longitude of Dakar $\left(342.74^{\circ} \mathrm{E}\right) \mathrm{ob}-$ tained with International Reference Ionosphere model, IRI2016, as an example for January, at $15 \mathrm{LT}$ and solar activity level corresponding to F10.7 $=150$. Dashed line indicates de latitude of Dakar. From 1964 to 1996 foF2 decrease at latitude of Dakar.

Ouagadougou located near the trough is approaching it and a decrease in the trend is expected. This is the case with the trend of $-0.015 \mathrm{MHz} /$ year obtained by [15]. 
Huancayo is in a similar geographic location to Dakar. It is an equatorial ionospheric station located north of the magnetic dip equator but in the southern hemisphere. In this case, the magnetic dip equator moves away from the station, so we should expect an increase in foF2. foF2 trend for this station was evaluated by [43] which obtained a positive value of $0.017 \mathrm{MHz} /$ year, qualitatively in agreement with the displacement of the EIA trough.

PhuThuy is located near the northern crest of the EIA and is approaching it, an increase in foF2 should be expected. [46] obtained a positive trend of 0.025 $\mathrm{MHz} /$ year which is qualitatively in agreement with the expected trend.

\section{Conclusion}

The study shows that increase in greenhouse gases concentration, geomagnetic activity and secular variations of inclination I and declination D have a very limited effect on foF2 long-term trends at Dakar station. Earth's magnetic field magnitude $B$ secular variations and dip equator displacement seem to be the main causes of the decreasing trends of foF2 observed at Dakar station between $1200 \mathrm{LT}$ and $1700 \mathrm{LT}$. It would be important for other studies to be able to quantify dip equator displacement influence and geomagnetic activity on foF2 long-term trends in this EIA region. This quantification will allow us to determine the relative influences of greenhouse gases, geomagnetic activity and the variation of inclination I and declination D compared to the Earth's magnetic field magnitude $B$ variations of $B$ and dip equator displacement.

\section{Conflicts of Interest}

The authors declare no conflicts of interest regarding the publication of this paper.

\section{References}

[1] Lastovicka, J., Solomon, S.C. and Qian, L. (2012) Trends in the Neutral and Ionized Upper Atmosphere. Space Science Reviews, 168, 113-145. https://doi.org/10.1007/s11214-011-9799-3

[2] Roble, R. and Dickinson, R. (1989) How Will Changes in Carbon Dioxide and Methane Modify the Mean Structure of the Mesosphere and Thermosphere? Geophysical Research Letters, 16, 1441-1444. https://doi.org/10.1029/GL016i012p01441

[3] Akmaev, R. and Fomichev, V. (2000) A Model Estimate of Cooling in the Mesosphere and Lower Thermosphere Due to the $\mathrm{CO}_{2}$ Increase over the Last 3-4 Decades. Geophysical Research Letters, 27, 2113-2116. https://doi.org/10.1029/1999GL011333

[4] Akmaev, R., Fomichev, V. and Zhu, X. (2006) Impact of Middle-Atmospheric Composition Changes on Greenhouse Cooling in the Upper Atmosphere. Journal of Atmospheric and Solar-Terrestrial Physics, 68, 1879-1889. https://doi.org/10.1016/j.jastp.2006.03.008

[5] Bremer, J. (1998) Trends in the Ionospheric E and F Regions over Europe. Annales Geophysicae, 16, 986-996. https://doi.org/10.1007/s00585-998-0986-9

[6] Bremer, J. and Berger, U. (2002) Mesospheric Temperature Trends Derived from 
Ground-Based LF Phase-Height Observations at Mid-Latitudes: Comparison with Model Simulations. Journal of Atmospheric and Solar-Terrestrial Physics, 64, 805-816. https://doi.org/10.1016/S1364-6826(02)00073-1

[7] Bremer, J. and Peters, D. (2008) Influence of Stratospheric Ozone Changes on Long-Term Trends in the Meso- and Lower Thermosphere. Journal of Atmospheric and Solar-Terrestrial Physics, 70, 1473-1481. https://doi.org/10.1016/j.jastp.2008.03.024

[8] Bremer, J., et al. (2006) Long-Term Changes of Mesospheric Summer Echoes at Polar and Middle Latitudes. Journal of Atmospheric and Solar-Terrestrial Physics, 68, 1940-1951. https://doi.org/10.1016/j.jastp.2006.02.012

[9] Bremer, J., et al. (2009) Climate of the Upper Atmosphere. Annals of Geophysics, 52, 273-299.

[10] Cnossen, I. and Richmond, A.D. (2008) Modelling the Effects of Changes in the Earth's Magnetic Field from 1957 to 1997 on the Ionospheric hmF2 and foF2 Parameters. Journal of Atmospheric and Solar-Terrestrial Physics, 70, 1512-1524. https://doi.org/10.1016/j.jastp.2008.05.003

[11] Danilov, A. and Konstantinova, A. (2015) Variations in foF2 Trends with Season and Local Time. Geomagnetism and Aeronomy, 55, 51-58.

https://doi.org/10.1134/S0016793215010041

[12] Danilov, A. (2002) The Method of Determination of the Long-Term Trends in the F2 Region Independent of Geomagnetic Activity. Annals of Geophysics, 20, 511-521. https://doi.org/10.5194/angeo-20-511-2002

[13] Danilov, A. (2009) Critical Frequency foF2 as an Indicator of Trends in Thermospheric Dynamics. Journal of Atmospheric and Solar-Terrestrial Physics, 71, 1430-1440. https://doi.org/10.1016/j.jastp.2008.04.001

[14] Elias, A.G. (2009) Trends in the F2 Ionospheric Layer Due to Long-Term Variations in the Earth's Magnetic Field. Journal of Atmospheric and Solar-Terrestrial Physics, 71, 1602-1609. https://doi.org/10.1016/j.jastp.2009.05.014

[15] Gnabahou, D.A., Elias, A.G. and Ouattara, F. (2013) Long-Term Trend of foF2 at a West African Equatorial Station Linked to Greenhouse Gas Increase and Dip Equator Secular Displacement. Journal of Geophysical Research: Space Physics, 118, 3909-3913. https://doi.org/10.1002/jgra.50381

[16] Jarvis, M., Clilverd, M. and Ulich, T. (2002) Methodological Influences on F-Region Peak Height Trend Analyses. Physics and Chemistry of the Earth, Parts A/B/C, 27, 589-594. https://doi.org/10.1016/S1474-7065(02)00041-4

[17] Lastovicka, J. (2002) Long-Term Changes and Trends in the Lower Ionosphere. Physics and Chemistry of the Earth, Parts $A / B / C, 27,497-507$. https://doi.org/10.1016/S1474-7065(02)00031-1

[18] Lastovicka, J. (2012) On the Role of Ozone in Long-Term Trends in the Upper Atmosphere-Ionosphere System. Annals of Geophysics, 30, 811-816. https://doi.org/10.5194/angeo-30-811-2012

[19] Lastovicka, J. and Bremer, J. (2004) An Overview of Long-Term Trends in the Lower Ionosphere below $120 \mathrm{~km}$. Surveys in Geophysics, 25, 69-99. https://doi.org/10.1023/B:GEOP.0000015388.75164.e2

[20] Lastovicka, J. and Jelínek, Š. (2019) Problems in Calculating Long-Term Trends in the Upper Atmosphere. Journal of Atmospheric and Solar-Terrestrial Physics, 189, 80-86. https://doi.org/10.1016/j.jastp.2019.04.011

[21] Lastovicka, J., et al. (2006) Long-Term Trends in foF2: A Comparison of Various 
Methods. Journal of Atmospheric and Solar-Terrestrial Physics, 68, 1854-1870. https://doi.org/10.1016/j.jastp.2006.02.009

[22] Lastovicka, J., Akmaev, R., Beig, G., Bremer, J. and Emmert, J. (2006) Global Change in the Upper Atmosphere. Science, 314, 1253-1254.

https://doi.org/10.1126/science.1135134

[23] Lastovicka, J., et al. (2008) Emerging Pattern of Global Change in the Upper Atmosphere and Ionosphere. Annals of Geophysics, 26, 1255-1268. https://doi.org/10.5194/angeo-26-1255-2008

[24] Lastovicka, J., Yue, X. and Wan, W. (2008) Long-Term Trends in foF2: Their Estimating and Origin. Annals of Geophysics, 26, 593-598. https://doi.org/10.5194/angeo-26-593-2008

[25] Mikhailov, A. (2002) The Geomagnetic Control Concept of the F2-Layer Parameter Long-Term Trends. Physics and Chemistry of the Earth, Parts A/B/C, 27, 595-606. https://doi.org/10.1016/S1474-7065(02)00042-6

[26] Mikhailov, A. (2006) Ionospheric Long-Term Trends: Can the Geomagnetic Control and the Greenhouse Hypotheses Be Reconciled? Annals of Geophysics, 24, 2533-2541. https://doi.org/10.5194/angeo-24-2533-2006

[27] Mikhailov, A. and Marin, D. (2000) Geomagnetic Control of the foF2 Long-Term Trends. Annales Geophysicae, 18, 653-665. https://doi.org/10.1007/s00585-000-0653-2

[28] Mikhailov, A. and Marin, D. (2001) An Interpretation of the? oF2 and hmF2 Long-Term Trends in the Framework of the Geomagnetic Control Concept. Annales Geophysicae, 19, 733-748. https://doi.org/10.5194/angeo-19-733-2001

[29] Ortiz De Adler, N.O., Elias, A.G. and Heredia, T. (2002) Long-Term Trend of the Ionospheric F2 Layer Peak Height at a Southern Low Latitude Station. Physics and Chemistry of the Earth, Parts $A / B / C, 27,613-615$. https://doi.org/10.1016/S1474-7065(02)00044-X

[30] Ouattara, F. (2012) foF2 Long Term Trends at Ouagadougou Station. Current Journal of Applied Science and Technology, 2, 240-253. https://doi.org/10.9734/BJAST/2012/1552

[31] Qian, L., Solomon, S.C., Roble, R.G. and Kane, T.J. (2008) Model Simulations of Global Change in the Ionosphere. Geophysical Research Letters, 35, L07811. https://doi.org/10.1029/2007GL033156

[32] Rishbeth, H. (1997) Long-Term Changes in the Ionosphere. Advances in Space Research, 20, 2149-2155. https://doi.org/10.1016/S0273-1177(97)00607-8

[33] Ulich, T., Clilverd, M.A. and Rishbeth, H. (2003) Determining Long-Term Change in the Ionosphere. Eos, Transactions American Geophysical Union, 84, 581-585. https://doi.org/10.1029/2003EO520002

[34] Ulich, T., Clilverd, M.A., Jarvis, M.J. and Rishbeth, H. (2007) Unravelling Signs of Global Change in the Ionosphere. In: Space Weather, Springer, Berlin, 95-105. https://doi.org/10.1007/1-4020-5446-7_10

[35] Xu, Z., Wu, J., Igarashi, K., Kato, H. and Wu, Z. (2004) Long-Term Ionospheric Trends Based on Ground-Based Ionosonde Observations at Kokubunji, Japan. Journal of Geophysical Research: Space Physics, 109, A09307. https://doi.org/10.1029/2004JA010572

[36] Yue, X., Liu, L., Wan, W., Wei, Y. and Ren, Z. (2008) Modeling the Effects of Secular Variation of Geomagnetic Field Orientation on the Ionospheric Long Term Trend over the Past Century. Journal of Geophysical Research: Space Physics, 113, A10301. https://doi.org/10.1029/2007JA012995 
[37] Elias, A.G. (2011) Possible Sources of Long-Term Variations in the Mid-Latitude Ionosphere. The Open Atmospheric Science Journal, 511, 9-15. https://doi.org/10.2174/1874282301105010009

[38] Danilov, A. and Mikhailov, A. (1998) Long-Term Trends of the F2-Layer Critical Frequencies: A New Approach. In: Proceedings of the 2nd COST 251 Workshop “Algorithms and Models for COST 251 Final Product", Rutherford Appleton Laboratory, Didcot, 114-121.

[39] Danilov, A. and Mikhailov, A. (1999) Long-Term Trends in the Parameters of the F2 Region: A New Approach. Geomagnetism and Aeronomy Cc Geomagnetism and Aeronomy, 39, 473-479.

[40] Bremer, J. (2008) Long-Term Trends in the Ionospheric E and F1 Regions. Annals of Geophysics, 26, 1189-1197. https://doi.org/10.5194/angeo-26-1189-2008

[41] Rishbeth, H. (1990) A Greenhouse Effect in the Ionosphere? Planetary and Space Science, 38, 945-948. https://doi.org/10.1016/0032-0633(90)90061-T

[42] Rishbeth, H. and Roble, R. (1992) Cooling of the Upper Atmosphere by Enhanced Greenhouse Gases-Modelling of Thermospheric and Ionospheric Effects. Planetary and Space Science, 40, 1011-1026. https://doi.org/10.1016/0032-0633(92)90141-A

[43] Upadhyay, H.O. and Mahajan, K. (1998) Atmospheric Greenhouse Effect and Ionospheric Trends. Geophysical Research Letters, 25, 3375-3378. https://doi.org/10.1029/98GL02503

[44] Bremer, J., Damboldt, T., Mielich, J. and Suessmann, P. (2012) Comparing LongTerm Trends in the Ionospheric F2-Region with Two Different Methods. Journal of Atmospheric and Solar-Terrestrial Physics, 77, 174-185. https://doi.org/10.1016/j.jastp.2011.12.017

[45] Rishbeth, H. (1998) How the Thermospheric Circulation Affects the Ionospheric F2-Layer. Journal of Atmospheric and Solar-Terrestrial Physics, 60, 1385-1402. https://doi.org/10.1016/S1364-6826(98)00062-5

[46] Pham Thi Thu, H., Amory-Mazaudier, C. and Le Huy, M. (2011) Time Variations of the Ionosphere at the Northern Tropical Crest of Ionization at Phu Thuy, Vietnam. Annals of Geophysics, 29, 197-297.

https://doi.org/10.5194/angeo-29-197-2011 